Goldschmidt 2021 Abstract

https://doi.org/10.7185/gold2021.6841 the overall iron cycling shortly before and during the SmithianSpathian biotic crisis interval.

\section{A positive iron isotope excursion recorded in micropyrites at the Smithian-Spathian (Early Triassic) boundary}

MARIE-NOËLLE DECRAENE ${ }^{1}$, JOHANNA MARINCARBONNE $^{1}$, DR. CHRISTOPHE THOMAZO ${ }^{2}$, DR. ANNESOPHIE BOUVIER, PHD $^{3}$, ARNAUD BRAYARD ${ }^{4}$ AND NICOLAS OLIVIER ${ }^{5}$

${ }^{1}$ Université de Lausanne

${ }^{2}$ Laboratoire Biogéosciences, UMR CNRS 6282, Université de Bourgogne Franche-Comté

${ }^{3}$ ISTE - University of Lausanne

${ }^{4}$ Université Bourgogne Franche-Comté

${ }^{5}$ Université Clermont Auvergne

Presenting Author: marie-noelle.decraene@unil.ch

In the aftermath of the end-Permian mass extinction, the Early Triassic have undergone various, repeated environmental stresses resulting in another biotic extinction at the Smithian-Spathian boundary (SSB). This event is also coeval to major perturbations of the carbon, oxygen, nitrogen and sulfur cycles. These are diagnostic of an extended anoxia, an abrupt climate warmingcooling swing, changes in productivity and microbial redox cycles. Even if geochemical proxies describe globally harsh environmental conditions, shallow marine environments are thought to have been well oxygenated and should have offered favorable environments for a rapid biotic recovery. These environments are well illustrated by the Thaynes Group in the western USA basin, where for instance microbially induced sedimentary structures (MISS) commonly occur. In order to further precise the regional redox budget and to characterize microbial activity across the SSB, iron isotopic signatures $\left(\delta^{56} \mathrm{Fe}\right)$ of sedimentary micropyrites from the Lower Weber Canyon section (northeastern Utah) have been measured by SIMS on 8 samples representing 3 lithologies (dolosiltstones, bioclastic limestones and silty marls). These samples reflect a ramp system, including the siliciclastic inner-ramp, the storm-dominated midramp and the mud-dominated mid to outer-ramp. A large iron isotopic variability is evidenced from the late Smithian to the early Spathian, with $\delta^{56} \mathrm{Fe}$ values ranging from $-1.1 \%$ to $+5.1 \%$. Dolosiltstones of the late Smithian can be dissociated in two subfacies: a dolosilty matrix with micropyrites characterized by a mean $\delta^{56} \mathrm{Fe}$ value of $\sim+0.9 \%$ and organic-matter rich laminae (MISS) with micropyrites characterized by a mean $\delta^{56} \mathrm{Fe}$ value of $\sim+2.0 \%$. A shift toward positive $\delta^{56} \mathrm{Fe}$ mean values is recorded across the SSB in bioclastic limestones, from $+0.6 \%$ to $+2.7 \%$ o followed by a $\mathrm{Fe}$ isotopic signal decreases down to $\sim+1.0 \%$ during the early Spathian. Overall, our results do not show a control of the sedimentary depositional environment on $\mathrm{Fe}$ isotopic compositions. Nonetheless, ${ }^{56} \mathrm{Fe}$-enrichments are preferentially observed in organic-rich samples corresponding to MISS of the late Smithian and organic carbon enriched and heavy $\delta^{34} \mathrm{~S}_{\mathrm{py}}$ limestones of the $\mathrm{SSB}$, which may suggest a direct influence of microbial metabolisms, possibly sulfato-reducers, on 